\title{
OESOPHAGUS
}

\section{Efficacy and one year follow up of argon plasma coagulation therapy for ablation of Barrett's oesophagus: factors determining persistence and recurrence of Barrett's epithelium}

\author{
K K Basu, B Pick, R Bale, K P West, J S de Caestecker
}

Gut 2002;51:776-780

See end of article for authors' affiliations

Correspondence to: Dr K K Basu, Department of Gastroenterology, Northern General Hospital, Herries Road, Sheffield S5 7AU,

UK

kumar.Basu@

northngh-tr.trent.nhs.uk

Accepted for publication 26 June 2002
Introduction: Barrett's epithelium (BE) has malignant potential. Neither acid suppression nor antireflux surgery produce consistent or complete regression of the metaplastic epithelium. Endoscopic thermoablation with argon plasma coagulation (APC) offers a different approach but factors influencing its outcome have not been systematically examined.

Aim: To assess the efficacy of APC and factors influencing initial and one year outcome.

Methods: Fifty patients, mean age 61.4 years, mean BE length $5.9 \mathrm{~cm}$ (range 3-19), underwent APC therapy at four weekly intervals while receiving proton pump inhibitor (PPI) therapy. BE margins were marked by India ink tattooing and extent was documented by grid drawings, photography, and $2 \mathrm{~cm}$ interval quadrantic jumbo biopsies. Twenty four hour ambulatory oesophageal $\mathrm{pH}$ studies were done while on PPIs before and after APC therapy, and Bilitec bilirubin monitoring after APC completion.

Results: A total of $68 \%$ of patients achieved $>90 \%$ BE ablation after a median of four APC sessions. Persistent $B E(>10 \%$ original $B E$ area) was associated with longer initial BE length despite more APC sessions. Persistent acid and bile reflux on PPIs, although commoner in this group, were not significantly different from those successfully ablated. Fifteen of 34 patients $(44 \%)$ with successful macroscopic clearance had buried glands, present in $8.3 \%$ of a total of 338 biopsies. At the one year follow up, only $32 \%$ of those with initial successful ablation showed no recurrence. BE recurred or increased in most with mean segment length increases of $1.1 \mathrm{~cm}$ and $1.6 \mathrm{~cm}$, respectively, in patients with previous full ablation and those with persistent BE. The presence of buried glands did not predict BE recurrence. Patients who reduced their PPI dose had significantly greater BE recurrence.

Conclusions: APC is most effective for shorter segment BE ablation but "buried" glands do occur. Recurrence of $B E$ is common at one year, especially in those with initial persistent and/or long segment $\mathrm{BE}$ and those who reduce their PPI dose.
$\mathrm{B}$ rrett's epithelium (BE) is a premalignant condition secondary to severe chronic gastro-oesophageal reflux. ${ }^{1}$ Prospective endoscopic surveillance studies estimate the incidence of oesophageal adenocarcinoma at approximately 1:100 patient years. ${ }^{2}$ High risk factors include increasing length of $\mathrm{BE},{ }^{34}$ male sex, ${ }^{5}$ presence of dysplasia, ${ }^{6}$ and possibly duodenogastro-oesophageal reflux. ${ }^{7}$

Current management of BE includes endoscopic surveillance which remains contentious due to both the significant morbidity and mortality associated with oesophagectomy for high grade dysplasia or early adenocarcinoma ${ }^{89}$ and the lack of conclusive evidence of cost benefit. The aim of medical therapy is to reduce acid reflux using potent acid suppressant agents such as proton pump inhibitors (PPIs). Antireflux surgery is also advocated for reflux control, particularly for those with inadequate response or intolerance of pharmacological therapy. Unfortunately, neither of these approaches has been shown to induce consistent or complete BE regression. ${ }^{10-12}$

This has led to examination of new endoscopic thermoablative techniques in the setting of acid suppression. ${ }^{13}$ Argon plasma coagulation (APC) is an example of one such technique ${ }^{14}$ which has advantages over laser therapy in being cheaper, more portable, and theoretically safer. The ultimate aim of this therapy is to reduce malignant potential which is related to the presence of BE. A number of studies have reported on the efficacy of APC for BE ablation ${ }^{15-17}$ : however, follow up patient numbers are small and the long term stability of the resulting neosquamous epithelium remains unclear.
Our aims were therefore to assess the efficacy of APC for BE ablation and to investigate factors influencing the outcome of therapy and stability of the neosquamous epithelium after one year of follow up in a cohort of 50 patients.

\section{PATIENTS AND METHODS \\ Patients}

Patients were recruited from a local BE database. All had $\geqslant 3 \mathrm{~cm}$ of columnar lined oesophagus (with specialised intestinal metaplasia on histology) above the gastro-oesophageal junction which was defined endoscopically as the most proximal margins of the gastric longitudinal folds. ${ }^{18}$ Written informed consent in all and local ethics approval were obtained. Exclusions included those with serious comorbidity-that is, severe cardiac or respiratory diseasedisseminated cancer, intolerance to endoscopy, inability to take PPIs, use of anticoagulants, steroids or regular nonsteroidal anti-inflammatory drugs, history of previous gastrooesophageal surgery, and any patient with confirmed or previous high grade dysplasia or oesophageal cancer.

\section{Medication}

All patients were established on PPI regimens, usually omeprazole $20 \mathrm{mg}$ twice daily or lansoprazole $30 \mathrm{mg}$ daily to

Abbreviations: $\mathrm{BE}$, Barrett's epithelium; PPI, proton pump inhibitor; APC, argon plasma coagulation. 
achieve adequate acid suppression (assessed by 24 hour oesophageal $\mathrm{pH}$ measurement, see below) defined as the total time ( 24 hours) oesophageal $\mathrm{pH}$ was $<4$ less than $1.6 \%$ in concordance with normal values for controls on twice daily PPIs. ${ }^{19}$ In patients with acid reflux breakthrough, the PPI dose was increased to omeprazole $60 \mathrm{mg}$ daily in divided doses.

\section{Oesophageal studies}

Prior to endoscopic ablation, all patients underwent standard oesophageal manometry followed by 24 hour ambulatory oesophageal pH monitoring (Synectics Medical Inc., USA) while on PPI therapy using an antimony $\mathrm{pH}$ catheter placed $5 \mathrm{~cm}$ above the manometrically located lower oesophageal sphincter. Where necessary the dose of PPI was increased as indicated above. The $\mathrm{pH}$ and manometry measurements were repeated at least six weeks after completion of APC ablation therapy, with the addition of 24 hour ambulatory oesophageal bilirubin monitoring (Bilitec 2000 system; Synectics Inc ${ }^{20}$ ) as a means of detecting duodenogastro-oesophageal reflux. The normal value for bile reflux was taken as per cent of time over 24 hours that absorbance was greater than 0.14 units $<2.9 \%{ }^{21}$ Meal times were standardised, and for Bilitec monitoring a specialised diet including avoidance of solid foods and foods with a similar absorbance spectrum to bilirubin was employed.

\section{BE extent}

The proximal and distal margins of BE were marked using India ink tattooing during the first visit and extent was documented using endoscopic grid drawings and photography.

\section{Histology}

Quadrantic $2 \mathrm{~cm}$ interval jumbo biopsies were taken for histological confirmation of BE prior to ablation and at study completion to document normal squamous re-epithelialisation and look for evidence of "buried" BE glands. All samples were assessed by a single experienced dedicated histopathologist with a special interest in gastrointestinal histopathology (KPW).

\section{Argon plasma coagulation (APC)}

Endoscopy was performed on a day case basis using intravenous midazolam sedation (Hypnovel, Roche, Welwyn Garden City, Herts, UK; 2.5-10 mg), topical lignocaine spray (Xylocaine 10\%; Astra, Kings Langley, Herts, UK), and hyoscine butylbromide (Buscopan, Boehringer Ingelheim, Bracknell, Berkshire, UK) 20-40 mg intravenously to inhibit oesophageal peristalsis. Pulse oximetry and blood pressure were recorded throughout the procedures. Using an Erbe APC 300 system (Erbe Medical UK Ltd, Leeds, UK) and Erbe gastrointestinal flexible probes, APC was delivered at a 30 watt setting at four weekly intervals aiming to treat one third of the oesophageal circumference per session until macroscopic clearance was achieved. For shorter segment BE and islands, point application was used and for larger areas longitudinal "stroking" of the probe in a caudal to cranial direction was employed to achieve a white coagulum thermal injury. Any patient symptoms were recorded and patients were contacted by telephone 24 hours post treatment to assess for complications. Failure of treatment was arbitrarily defined as $\geqslant 10 \%$ of the original Barrett's area persisting despite ablative treatment to that area on at least two occasions. Thus where it was clear after two sessions that no squamous re-epthelialisation had occurred, the patient was deemed a treatment failure. Patients in whom some effect was noted continued in the study to a maximum of eight sessions (see results below) after which the final area of residual BE was calculated.

\section{One year follow up}

Patients and their general practitioners were instructed to continue the same dose of PPIs used during the study and underwent endoscopic review at one year following completion of treatment during which BE extent, if any, was redocumented and biopsies taken from the previous original levels for histological examination. Medication at follow up was reviewed based on self reporting.

\section{Statistics}

The effects of persistent acid reflux, bile reflux, initial extent of $\mathrm{BE}$ segment length, and patient age on initial efficacy of APC therapy were compared. The presence of BE recurrence after one year of follow up was also examined in relation to the previous efficacy of ablation, presence of buried glands, degree of acid and bile reflux, and change in PPI dose. The Mann-Whitney $U$ test (adjusted for ties with two sided $p$ values) and Fisher's exact test were used as appropriate (Arcus Quickstat Biomedical, Cambridge Sciences Park, Cambridge, UK version 1.1).

\section{RESULTS}

\section{Initial efficacy of APC ablation}

Fifty patients completed a course of APC ablation therapy after a median of four sessions (range 1-8). Mean age was 61.4 years (SD 1 1.5, range 28-80). Mean BE length was $5.9 \mathrm{~cm}$ (SD 3.1 , range $3-19)$. Thirty four $(68 \%)$ patients achieved $\geqslant 90 \%$ BE clearance (30 with $100 \%$ clearance) and 16 patients had persistent BE; most of these achieved at least $50 \%$ ablation. Squamous re-epithelialisation was confirmed histologically in all patients. "Buried" BE glands occurred in 15 of 34 patients (44\%), with successful macroscopic clearance representing 28 of 338 biopsies $(8.3 \%)$. Nine of $16(56 \%)$ patients with persistent BE had "buried" glands in six of 133 biopsies (19.5\%). Overall "buried" glands occurred in 54 of 471 biopsies ( $11.5 \%)$ in $24(48 \%)$ patients.

\section{Safety of APC ablation}

APC was well tolerated using minor sedation. Mean duration of APC application was 9.1 minutes (range 1-20). Side effects were self limiting and comprised central chest discomfort after $32 \%$ of APC sessions, odynophagia after $25 \%$, and temporary dysphagia associated with superficial ulceration after $4 \%$. No interventions were required. No strictures or bleeding occurred.

\begin{tabular}{|c|c|c|c|c|}
\hline APC outcome & $\begin{array}{l}\text { Mean (SD) } \\
\text { age }(y)\end{array}$ & $\begin{array}{l}\text { Mean (SD) } \\
\text { BE length }(\mathrm{cm})\end{array}$ & $\begin{array}{l}\text { Median No of } \\
\text { APC sessions }\end{array}$ & $\begin{array}{l}\text { Median \% total } \\
\text { time } \mathrm{pH}<4 \text { (IQR) }\end{array}$ \\
\hline $\begin{array}{l}\text { Successful ablation ( } n=34) \\
\text { Persistent BE }(n=16)\end{array}$ & $\begin{array}{l}60.6(10.9) \\
63.2(12.9)\end{array}$ & $\begin{array}{l}4.7(1.8) \\
8.4(3.7)^{*}\end{array}$ & $\begin{array}{l}3 \\
4.5 * *\end{array}$ & $\begin{array}{l}0(0-0.5) \\
0.7(0-1.8)\end{array}$ \\
\hline
\end{tabular}


Table 2 Bile reflux in 31 Barrett's epithelium (BE) patients after argon plasma coagulation (APC) therapy

\begin{tabular}{llllr}
\hline APC outcome & $\begin{array}{l}\text { Mean (SD) } \\
\text { age }(y)\end{array}$ & $\begin{array}{l}\text { Mean (SD) } \\
\text { BE length (cm) }\end{array}$ & $\begin{array}{l}\text { Median No of } \\
\text { APC sessions }\end{array}$ & $\begin{array}{l}\text { Median \% total time } \\
\text { absorbance }>0.14 \\
\text { units (IQR) }\end{array}$ \\
\hline $\begin{array}{l}\text { Successful ablation }(n=23) \\
\text { Persistent BE }(n=8)\end{array}$ & $62.6(9.8)$ & $4.5(1.6)$ & 3 & $7.5(4.3-18.4)$ \\
\hline $\begin{array}{l}\text { Not all patients were willing/able to undergo Bilitec monitoring. } \\
{ }^{*} p<0.0001 ;{ }^{* *} p=0.01 .\end{array}$
\end{tabular}

Table 3 Comparison of Barrett's epithelium (BE) recurrence at one year between patients with successful macroscopic versus those with persistent $B E$ after argon plasma coagulation (APC) ablation

\begin{tabular}{|c|c|c|c|}
\hline APC outcome & $\begin{array}{l}\text { Initial BE } \\
\text { length }(\mathrm{cm})\end{array}$ & $\begin{array}{l}\text { BE length at APC } \\
\text { completion }(\mathrm{cm})\end{array}$ & $\begin{array}{l}\text { One year follow up } \\
\text { BE length }(\mathrm{cm})\end{array}$ \\
\hline Successful ablation ( $n=34)$ & $4.7(1.8)$ & $0(0.1)$ & $1.1(1.1)$ \\
\hline Persistent BE $(n=16)$ & $8.4(3.7)$ & $3.9(4.5)$ & $5.5(4.5)$ \\
\hline
\end{tabular}

Table 4 Outcome of successful argon plasma coagulation (APC) macroscopic ablation in patients with and without buried glands at one year

\begin{tabular}{llllll}
\hline Successful ablation $(\mathrm{n}=34)$ & $\begin{array}{l}\text { Mean (SD) } \\
\text { initial BE } \\
\text { length }(\mathrm{cm})\end{array}$ & $\begin{array}{l}\text { Mean (SD) } \\
\text { one year BE } \\
\text { length }(\mathrm{cm})\end{array}$ & $\begin{array}{l}\text { Mean (SD) } \\
\text { age }(\mathrm{y})\end{array}$ & $\begin{array}{l}\text { Mean FU } \\
\text { interval } \\
\text { (months) }\end{array}$ & $\begin{array}{l}\text { Median \% } \\
\text { total time } \\
\mathrm{pH}<4(\mathrm{IQR})\end{array}$ \\
\hline $\begin{array}{l}\text { Buried glands not present }(\mathrm{n}=19) \\
\text { Buried glands }(\mathrm{n}=15)\end{array}$ & $5(1.8)$ & $1.2(1.3)$ & $62.2(10.5)$ & 14.5 & $0(0-0.4)$ \\
\hline BE, Barrett's epithelium; FU, follow up; IQR, interquartile range. & $4.4(1.8)$ & $1.1(0.9)$ & $58.7(11.4)$ & 13.8 & $0(0-0.5)$ \\
\hline
\end{tabular}

\section{Factors affecting squamous re-epithelialisation after APC ablation (tables 1, 2)}

Persistent $\mathrm{BE}(\mathrm{n}=16)$ was associated with longer initial $\mathrm{BE}$ segment length despite more APC sessions. Most had persistent tongues but six patients had greater than $50 \%$ of their circumferential BE persisting. There was a tendency for persistent acid and bile reflux to be commoner in this group although statistical significance was not achieved. As assessed by oesophageal $\mathrm{pH}$ monitoring at completion of APC therapy, only two patients had "pathological" acid reflux, defined as per cent daytime $\mathrm{pH}$ less than 4 exceeding $8.2 \%$ and/or night time acid reflux exceeding $3 \%,{ }^{22}$ and four others abnormal acid reflux compared with healthy volunteers on omeprazole $20 \mathrm{mg}$ twice daily (per cent total 24 hour time exceeding $1.6 \%) .{ }^{19}$ Bile reflux exceeded the normal range in $87 \%$ of patients despite PPI therapy.

\section{One year follow up after APC (table 3)}

All 50 patients attended for endoscopic follow up after a mean of 14 months post APC treatment. A mean of $1.1 \mathrm{~cm} \mathrm{BE} \mathrm{seg-}$

Table 5 Effect of reducing proton pump inhibitor (PPI) dose on Barrett's epithelium (BE) recurrence one year after argon plasma coagulation ablation

\begin{tabular}{lll}
\hline & $\begin{array}{l}\text { No of patients } \\
\text { on study dose } \\
\text { PPI medication }\end{array}$ & $\begin{array}{l}\text { No of patients } \\
\text { on reduced } \\
\text { PPI medication }\end{array}$ \\
\hline BE recurrence $(\mathrm{cm})$ \\
$<1.5$ & 29 \\
$>1.5$ & 9 & 4 \\
\hline Fisher's exact test $\mathrm{p}=0.01$ & 8 \\
\hline
\end{tabular}

ment length recurrence was seen in patients with initial $\mathrm{BE}$ clearance compared with a mean of $1.6 \mathrm{~cm}$ increase in $\mathrm{BE}$ segment length in those with persistent BE at the end of APC therapy $(p=0.06)$. Only 11 of 34 patients with initial total eradication of $\mathrm{BE}(32 \%)$ had no recurrent $\mathrm{BE}$ at follow up.

Effect of "buried" glands on BE recurrence at one year Patients with macroscopic clearance and no histological evidence of "buried" glands had a similar BE recurrence rate at one year compared with those with macroscopic clearance and buried glands (table 4). There were no significant differences in age, initial BE length, time of follow up, or degree of acid suppression between the two subgroups. At one year of follow up, "buried" glands occurred as a new finding in two of 19 previously clear patients, representing four (2\%) of 185 biopsies, and persisted in six of 15 patients with previous buried glands, representing 14 (9\%) of 148 biopsies.

Effect of reducing study PPI dose at one year (table 5)

Contrary to recommendations, 12 patients reduced their study PPI dose to omeprazole $20 \mathrm{mg}$ once daily or less. These patients had a significantly greater incidence of $\mathrm{BE}$ recurrence compared with those remaining on higher dose therapy.

\section{DISCUSSION}

APC ablative therapy proved to be safe and well tolerated, with only minor self limiting side effects. In particular, no strictures occurred, perhaps reflecting our policy of avoiding circumferential treatment in any one treatment session. Nearly $70 \%$ of patients achieved successful macroscopic ablation in keeping with other study findings ${ }^{15}$; however, buried glands were seen in a high proportion (44\%) of this group at histology. This may have resulted from the low energy settings used in our study. Recently, some workers ${ }^{23}$ have addressed this issue by adopting higher power APC settings to achieve more complete 
and potentially deeper ablation. This resulted in increased success in histological as well as macroscopic clearance of BE at the expense of more procedure related morbidity.

A substantial minority $(\mathrm{n}=16)$ failed therapy which we defined as $\geqslant 10 \%$ of the original Barrett's area persisting despite ablative treatment to that area on at least two occasions. Most treatment failures had persistent tongues but six patients had greater than $50 \%$ of their circumferential BE persisting. These patients had significantly longer mean initial BE segment length and a tendency to greater acid and bile reflux on PPI therapy. Bile reflux, a marker of duodenogastrooesophageal reflux, ${ }^{24}$ was common and exceeded normal established values in the majority of patients with or without successful BE ablation despite the acid suppressive effects of PPI therapy. It has been suggested that PPI therapy reduces duodenogastro-oesophageal reflux by reducing refluxate volume $^{25}$ but clearly the potential for significant bile reflux remains. This could be of particular importance in those with persistent $\mathrm{BE}$ as bile reflux has been suggested to increase the rate of complications, including neoplastic development. ${ }^{26}$

The reasons for reduced efficacy of $\mathrm{BE}$ ablation in longer segment patients is unclear and probably multifactorial. Long segment BE presents a greater technical challenge for ablation with a requirement for more treatment sessions, prolonged treatment times, and poorer patient tolerance. Acid has been shown to be increased in this group compared with short segment BE. ${ }^{27}$ The presence of contiguous squamous borders may promote new squamous re-epithelialisation after ablation of glandular mucosal ${ }^{28}$ and this is more likely to occur in shorter $\mathrm{BE}$ segments, especially with tongues and islands. The observed persistence of $\mathrm{BE}$ in this study is a disappointing result in that any BE remaining after ablation probably retains a malignant potential. It is not known whether reduction of $\mathrm{BE}$ segment length rather than complete ablation reduces future cancer risk.

For ablation therapy to be an effective strategy in reducing $\mathrm{BE}$ cancer incidence the neosquamous epithelium must be durable in the long term. After a mean follow up of 14 months, $\mathrm{BE}$ recurrence was seen in the majority of patients with only 11 of the original cohort of $50(22 \%)$ having no macroscopic or histological evidence of $\mathrm{BE}$. Those patients with persistent $\mathrm{BE}$ at completion of APC had a greater degree of recurrence at one year of follow up in comparison with those who had initial complete ablation.

An association of $\mathrm{BE}$ recurrence with reduced PPI maintenance dose was observed. This implies that continuing acid reflux suppression may be important in promoting persistence of the new squamous lining and patients undergoing ablation therapy should remain on high dose PPI medication. The results of studies combining ablation therapies with antireflux surgery (when available) may provide further support for this idea.

Concern exists about the presence of "buried" BE glands following ablation therapy. ${ }^{15} 29$ "Buried" glands may regress or may be clinically unimportant if protected from further acid/ alkaline assault by the neosquamous covering (that is, triggers for the progression along the dysplasia-cancer sequence) or may retain a malignant potential more difficult to detect at endoscopic surveillance ${ }^{30}$ This is of particular importance if practising ablation therapy in patients with dysplasia. Patients with high grade dysplasia were excluded from our study but two patients had low grade dysplasia apparently successfully ablated. At least two case reports exist in the literature of adenocarcinoma development after APC ablation. ${ }^{31}{ }^{32}$ Nevertheless, the presence of buried glands occurring in a sizeable minority of patients raises concerns about the ability to conduct endoscopic surveillance. To date, we have only followed up these patients for one year and clearly longer term follow up will be needed to address these issues.

Although buried glands were seen in many patients they only occurred in a minority of biopsies, and were slightly more prevalent in the presence of persistent BE. At one year of follow up only two new cases of patients with buried glands were seen. Overall the incidence of "buried" BE glands was unchanged in the subgroup of patients with successful macroscopic clearance after APC therapy at one year of follow up. Furthermore, the finding of buried glands at completion of APC did not appear to influence the likelihood of $\mathrm{BE}$ recurrence at one year.

In summary, initial longer segment length, persistent BE at completion of APC therapy, and reduction in PPI dose are associated with more BE recurrence one year after APC ablation therapy. The importance of bile reflux, although common, is less clear. Buried glands do not affect outcome at one year. Thus BE ablation is feasible but recurrence is common at one year. More aggressive ablation therapy may be effective but the risk benefit ratio in terms of cancer risk reduction versus side effects remains to be established. Nevertheless, we do not advocate APC intervention for patients with uncomplicated Barrett's mucosa and at present the only clinical indication for this possible form of intervention is established dysplasia, although even this remains experimental as long term follow up data have yet to be reported. This study has looked at the feasibility and durability of this technique. The relevance to clinical practice will emerge when biological markers to select those patients at high risk of developing dysplasia and carcinoma are identified.

\section{ACKNOWLEDGEMENTS}

Dr Basu was supported by a grant from Trent Regional R\&D. Part of the work in this report has been presented at BSG meetings and published in abstract form: Gut 2000; 46 (Suppl II): A93; Gut 2000; 46 (Suppl II): A95; Gut 2001; 48 (Suppl 1): A8.

\section{Authors' affiliations}

K K Basu, B Pick, R Bale, J S de Caestecker, Department of Gastroenterology, Glenfield Hospital, University Hospitals of Leicester NHS Trust, Leicester, UK

K P West, Department of Histopathology, Leicester Royal Infirmary, University Hospitals of Leicester NHS Trust, Leicester, UK

\section{REFERENCES}

1 Spechler SJ, Goyal RK. The columnar lined oesophagus, intestinal metaplasia and Norman Barrett. Gastroenterology 1996;110:614-22.

2 Drewitz DJ, Sampliner RE, Garewal HS. The incidence of adenocarcinoma in Barrett's oesophagus: a prospective study of 170 patients followed 4.8 years. Am J Gastroenterol 1997;92:212-15.

3 Iftikhar SY, James PD, Steele RJC, et al. Length of Barrett's oesophagus: an important factor in the development of dysplasia and adenocarcinoma. Gut 1992;33:1155-8.

4 Macdonald CE, Wicks AC, Playford RJ. Final results from 10 year cohort of patients undergoing surveillance for Barrett's oesophagus: observational study. BM 2000;321:1252-5.

5 Wright TA, Gray MR, Morris Al, et al. Cost effectiveness of detecting Barrett's cancer. Gut 1996;39:571-9.

6 Miros M, Kerlin P, Walker N. Only patients with dysplasia progress to adenocarcinoma in Barrett's oesophagus. Gut 1991;32:1441-6.

7 Vaezi MF, Singh S, Richter JE. Role of acid and duodenogastric reflux in esophageal mucosal injury: a review of animal and human studies. Gastroenterology 1995;108:1897-907.

8 Thomas $\mathbf{P}$, Doddoli C, Lienne $\mathrm{P}$, et al. Changing patterns and surgical results in adenocarcinoma of the oesophagus. Br J Surg 1997:84:119-25.

9 Ridell RH. Early detection of neoplasia of the oesophagus and gastroesophageal junction. Am J Gastroenterol 1996;91:853-63.

10 Neumann CS, lqbal TH, Cooper BT. Long term continuous omeprazole treatment of patients with Barrett's oesophagus. Aliment Pharmacol Ther 1995;9:451-4.

11 Sharma P, Sampliner RE, Carmargo E. Normalisation of esophageal pH with high dose proton pump inhibitor therapy does not result in regression of Barrett's esophagus. Am J Gastroenterol 1997;92:582-5.

12 Sagar PM, Ackroyd R, Hosie KB, et al. Regression and progression of Barrett's oesophagus after antireflux surgery. Br J Surg 1995;82:806-10.

13 de Caestecker JS. Endoscopic ablation of Barrett's epithelium. Eur J Gastroenterol Hepatol 1996;8:619-21

14 Johanns W, Luis W, Janssen J, et al. Argon plasma coagulation (APC) in gastroenterology: experimental and clinical experiences. Eur J Gastroenterol Hepatol 1997;9:581-9. 
15 Van Laethem J-L, Cremer M, Peny MO, et al. Eradication of Barrett's mucosa with argon plasma coagulation and acid suppression: immediate and mid-term results. Gut 1998;43:747-51

16 Schulz H, Miehlke S, Antos D, et al. Ablation of Barrett's epithelium by endoscopic argon plasma coagulation in combination with high-dose omeprazole. Gastrointest Endosc 2000;51:659-63.

17 Byrne JP, Armstrong, Attwood SE. Restoration of the normal squamous lining in Barrett's esophagus by argon beam plasma coagulation. Am J Gastroenterol 1998;93:1810-15.

18 McClave SA, Boyce HW, Gottfried MR. Early diagnosis of columnar-lined esophagus: a new endoscopic criterion. Gastrointest Endosc 1987;33:413-16.

19 Castell DO. Omeprazole works best when used properly. Eur J Gastroenterol Hepatol 1996:8:413-14.

20 Bechi $\mathbf{P}$, Pucciani $F$, Baldini $F$, et al. Long-term ambulatory enterogastric reflux monitoring. Validation of a new fibreoptic technique. Dig Dis Sci 1993;38: 1297-306

21 Kaver WKH, Peters JH, DeMeester TR, et al. Mixed reflux of gastric and duodenal juices is more harmful to the esophagus than gastric juice alone. Ann Surg 1995;222:525-33.

22 Klauser AG, Heinrich C, Schindlbeck NE, et al. Is long-term esophageal $\mathrm{pH}$ monitoring of clinical value? Am J Gastroenterol 1989;84:362-6.

23 Pereire-Lima JC, Busnello JV, Saul C, et al. High power setting argon plasma coagulation for the eradication of Barrett's esophagus. Am J Gastroenterol 2000;95:1661-8.
24 Champion G, Richter JE, Vaezi MF, et al. Duodenogastroesophageal reflux: relationship to $\mathrm{pH}$ and importance in Barrett's esophagus. Gastroenterology 1994;107:747-54

25 Marshall RE, Anggiansah A, Manifold DK, et al. Effect of omeprazole $20 \mathrm{mg}$ twice daily on duodenogastric and gastro-oesophageal bile reflux in Barrett's oesophagus. Gut 1998;43:603-6.

26 Stein HJ, Kaver WK, Feussner $\mathrm{H}$, et al. Bile reflux in benign and malignant Barrett's esophagus: effect of medical acid suppression and Nissen fundoplication. J Gastrointest Surg 1998;2:333-4 1

27 Fass R, Hell RW, Garewal HS, et al. Correlation of oesophageal acid exposure with Barrett's oesophagus length. Gut 2001;48:310-13.

28 Berenson MM, Johnson TD, Markowitz NR, et al. Restoration of squamous mucosa after ablation of Barrett's esophageal epithelium. Gastroenterology 1993:104:1686-91.

29 Grade AJ, Shah IA, Medlin SM, et al. The efficacy and safety of argon plasma coagulation therapy in Barrett's esophagus. Gastrointest Endosc 1999;50: 18-22.

30 Barham CP, Jones RL, Biddlestone LR, et al. Photothermal laser ablation of Barrett's oesophagus: endoscopic and histological evidence of squamous re-epithelialisation. Gut 1997:41:281-4.

31 Shand A, Dallal H, Palmer K, et al. Adenocarcinoma arising in columnar lined oesophagus following treatment with argon plasma coagulation. Gut 2001;48:580-1.

32 Van Laethem JL, Peny MO, Salmon I, et al. Intramucosal adenocarcinoma arising under squamous re-epithelialisation of Barrett's oesophagus. Gut 2000;46:574-7. 